\title{
On the Innervation of the Pupil of the Dog.
}

\section{Destruction of the Ganglion Ciliare of One Side.}

\author{
By \\ Zyun'itiro Ryû. \\ (笠 潤 一 郎) \\ (From the Institute of Physiology, Faculty of Medicine, \\ the Kyushu Imperial University, Hukuoka, \\ Director: Prof. M. Itagaki.)
}

\section{Symptoms and Progress.}

According to Elle $\mathrm{nberger}$ and $\mathrm{Ba} \mathrm{um}^{1 /}$ the ganglion ciliare is situated just close to the branching point of the lower branch of it from the stem of the oculomotor nerve. The shape is oval and flat. 2 or 3 short ciliary nerves, which left the ganglion ciliare ran forwards along the optic nerve and reached the sclera.

Operative procedure for extirpating g. ciliare.

After $1 / 3 \mathrm{cc}$ of $2 \%$ morphium hydrochlorium per kilo body weight was subcutaneously injected, the dog was fixed to an animal holder ventrally. After fixing, the head was rotated slightly directed to the opposite side to the operated side so that the operation may be carried on with ease. After shaving fur and disinfecting the region the longitudinal incision of the skin of about $3 \mathrm{~cm}$, which reached as far as the lower edge of the zygomatic arch was made about the middle between the meatus auditorius externus and the eye ball on the operated side.

After dividing muscles and finding the insertion point of the ligamentum orbitale and zygomatic arch, a part of both structures was extirpated. The outer wall of the orbita was then clearly shown. Then the incision was made down to the orbital membrane, corresponding to the position oft he $\mathrm{m}$. rectus post. and in getting deep into the orbital cavity we came across the pretty big nerve branch, which ran obliquely 
from below and in front to above and behined. This branch is a ventral branch of oculomotor nerve to the $m$. obliquus inf. Going ahead along this branch we come across a ganglion of millet-size near the branching place of the ventral and dorsal branches from the oculomotor nerve. Then the ganglion was crushed and destroyed by means of a pair of sharp pincettes.

* As soon as the ganglion ciliare was destroyed, the pupil dilated almost at its maximum $(11.2 \mathrm{~mm})$ and the reaction of the light entirely disappeared. We could not detect any strong myosis as Je gorow ${ }^{2}$ described, although there was a daily variation in the diameter of the pupil on the operated side during the course of our observation.

The pupil on the opposite side tended to contract slightly in every case, especially pronounced in Dog No. 18. This may be attributed to the increase of the tone in the centrum of a pupil as the result of increasing susceptibility for light stimulus of the retina as the pupil dilated at its maximum on the operated side.

\section{Pharmacological Experiments.}

\section{A. Drugsaugmenting parasympathetic nerve.}

\section{Pilocarpine.}

As Schultz ${ }^{3)}$ coulde not produce any myosis by the instillation of $5 \%$ physostigmine 4 days after the $\mathrm{g}$. ciliare had been extirpated, he concluded that physostigmine acted only on the ending of the short ciliary nerve. Anderson ${ }^{4)}$ found in the cat that when the oculomotor nerve was severed in the cranial cavity, pilocarpine produced a strong contraction on the pupil on the operated side, and physostigmine, on the contrary, showed only a slight action, whereas in both cases the action lasted long. After the degeneration of the short ciliary nerves, which had been severed, physostigmine did not stimulate the sphincter-muscle on the operated side and pilocarpine produced a strong myosis, which lasted for long period. Ara y a ${ }^{5}$ said that even the constricting action of $1: 200$ eserine upon the pupil of the side, in which the ciliary ganglion had been extirpated, once disappeared and again appeared 16 to 76 days after the operation and continued this state for a long period. Shen and $\mathrm{Cannon}{ }^{6)}$ instilled 2 drops of 1:10000 acetylcholine together with 2 drops of $1: 100$ eserine, which, used alone, was ineffective to the pupil, but effective for the prevention of the destructing action of acetylcholine, and by esterase they 
TABLE

The extirpation of

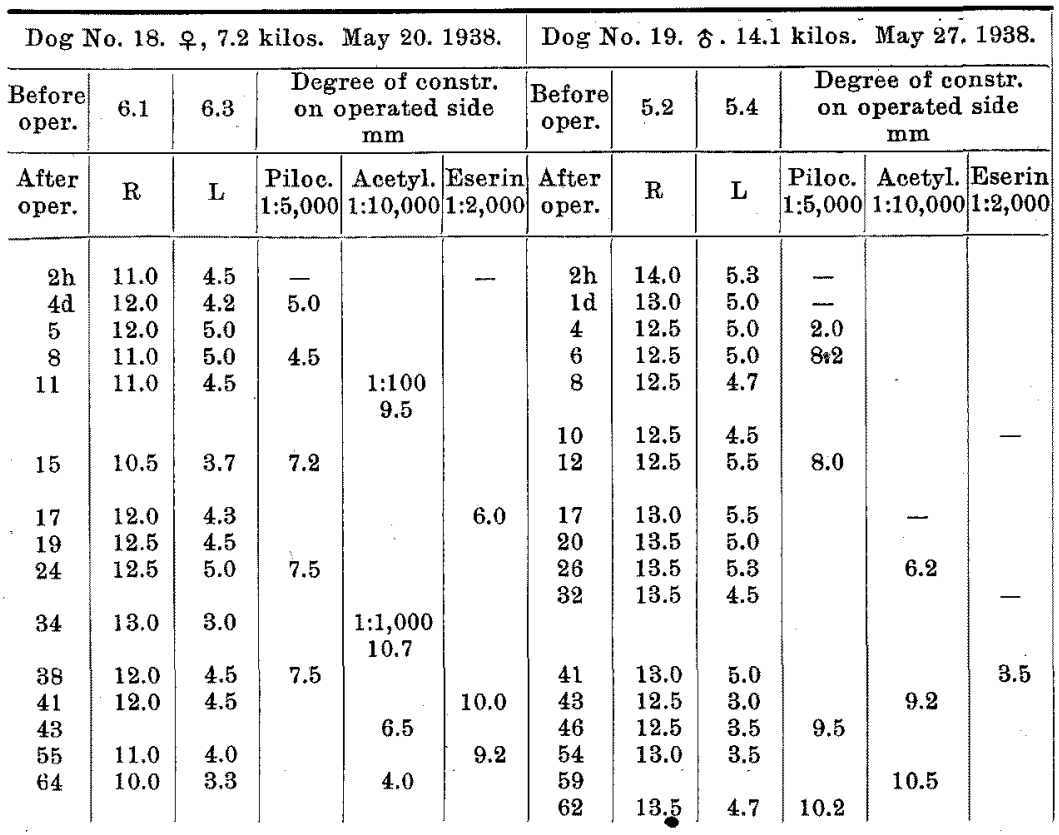

noticed a maximum mydriasis in the pupil on the side of the nerve severed.

In the present experiment we instilled 1 drop of $1: 1000-1: 5000$ pilocarpine solution, 2 drops of $1: 2000$ eserine and 1:1 000-1:10 000 acetylcholine, whereas in the latter case we instilled 1 drop of $1: 10$ 000 eserine previously. (Table I).

From the foregoing experiment we can conclude that when the g. ciliare is destroyed in the dog, the pupil on the operated side shows a marked myosis by the instillation of pilocarpine. With regard to this paradox myosis, which Anders on named, it was negative 2 hours after the operation in No. 1, (2 hours) and 21 hours in No. 2. In case No. 4 the pupil on the operated side showed a myosis of $5.2 \mathrm{~mm} 2$ days after the operation and in No. 1 and No. 2 this paradox pilocarpine myosis appeared. Thus as the day passes, the reaction of the pupil to pilocarpine increased gradually, reached almost its maximum after 6 days in No. 1,15 days in No. 2, 14 days in No. 3, and 7 days in No. 4 , maintaining about the same degree of the myosis for a while. 
I.

the right g. ciliare.

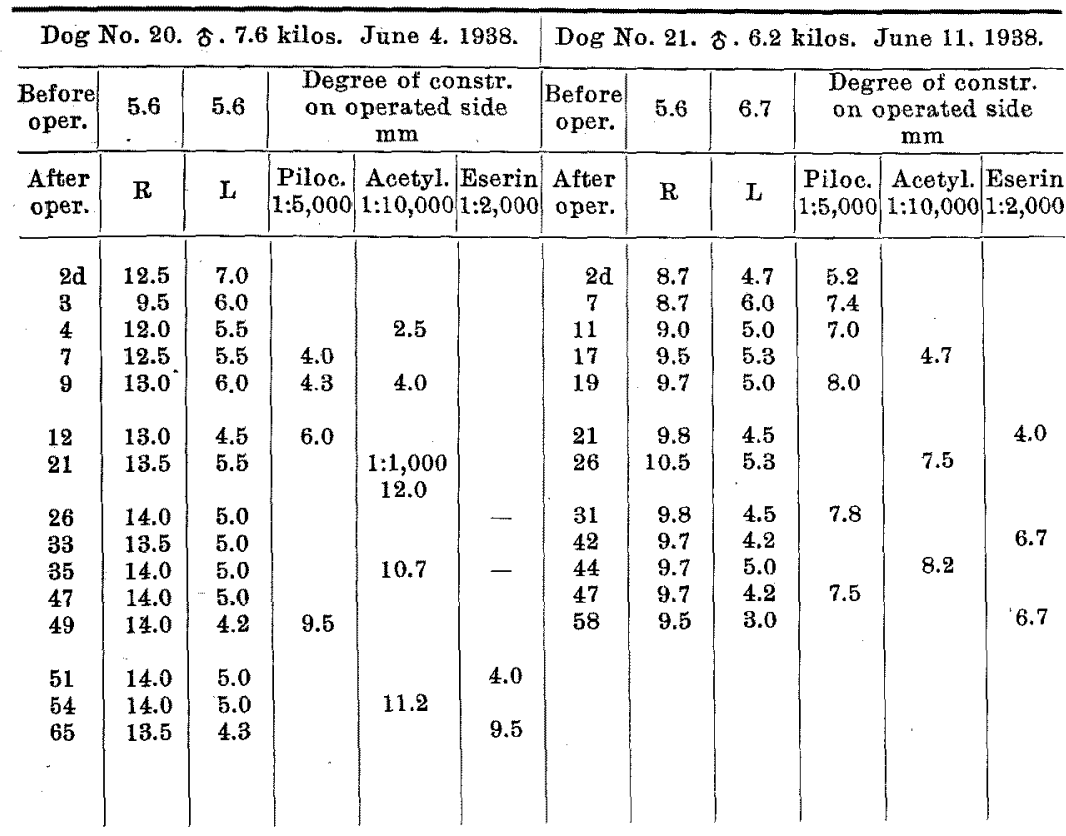

2. Acetylcholine.

In No. 3 we instilled 1 drop of $1: 10000$ eserine together with 1 drop of $1: 10000$ acetylcholine. 44 hours, 3 days after the operation no myosis was recognized but after 4 days a trifling effect was seen and after 9 days it showed a myosis of $4.3 \mathrm{~mm}$.

In No. 2 , the acetylcholine myosis was negative 17 days after the operation, and after 26 days it became positive.

In No. 4 the acetylcholine-myosis increased gradually 17,26 , and 44 days after the operation.

\section{Eserine.}

In No. 1 ( 5 days after the operation), No. 2 (10 and 32 days), No. 3 (26 and 33 days) eserine could not produce any myosis, but in No. 2 (41 days), No. 3 (47 days) No. 4 (21 days) it did. 
The action of pilocarpine, acetylcholine and eserine begins 15 minutes after the instillation, reaches its maximum after 45 minutes and then begins to dilate after 120 minutes and this dilation increases gradually. The pupil on the control healthy side takes the same progress of changes as that on the operated side and the degree of the latter is more pronounced.

In looking over the progress of the increase of the myosis by drugs we notice that there first appears the sensitivity to pilocarpine, then follows that to acetylcholine and then that to eserine.

\section{B. Drugs, augmenting sympathetic nerve.}

\section{Cocain and adrenaline.}

Exp. 1. Dog No. 18. 20 days after the extirpation of the g. ciliare.

After the instillation of 1 drop of $1: 5000$ pilocarpine the pupil of the operated side showed a myosis of $12.5 \mathrm{~mm}$ to $3.8 \mathrm{~mm}$. Then by the instillation of 3 drops of $1: 1000$ cocaine the operated side began to show a prompt and strong mydriasis which reached $12.5 \mathrm{~mm}$ after 90 minutes.

Exp. 2. (Dog No. 19) and Exp. 3 (Dog. No. 20). In these cases the similar results were obtained.

Exp. 3. The other series of experiments were tried. After the myosis appeared by the application of a small dose of pilocarpine, the instillation of 3 drops of 1:1 000 adrenaline hydrochloricum had no effect at all.

When the sympathetic innervation to the pupil became impaired, the action of cocain to it failed, and the sensitivity to adrenaline appeared as we described elsewhere before. Therefore it was proved that in our present experiment of extirpating a dog's ganglion ciliare we did not injure the sympathetic path at all.

\section{Drugs, paralysing parasympathetic nerves,}

\section{Atropine.}

Exp. 1. When the myosis of the operated side reached $6 \mathrm{~mm}$ after the instillation of $1: 5000$ pilocarpine, the instillation of 2 drops of * 1:100 000 atropine, caused $6 \mathrm{~mm}$ mydriasis after 60 minutes. This progress of the myosis was quicker and stronger than that on the control, healthy side.

Exp. 2. and Exp. 3. The results were similar. 
D. Drugs, paralysing sympathetic nerve.

\section{Ergotamine.}

Hess? studied the effect of the instillation of ergotamine on the cat and divided the action of it into 3 stages.

In the first stage appeard an uncertain light mydriasis.

In the second stage the strong myosis resulted from 2 causes of the impairment of the $\mathrm{m}$. dilatator pupillae and the exciting of the parasympathetic nerve.

The third stage, the light mydriasis and the diminution of the light reflex. By the instillation of 2 drops of $0.5 \%$ ergotamine the pupil of the cat showed a myosis of $7.0 \mathrm{~mm}$. According to the experiment of $\mathrm{PoOs}^{8)}$ on the isolated iris, ergotamine caused the increase of the tone of both $\mathrm{m}$. dilatator pupillae and $\mathrm{m}$. sphincter pupillae, and the ox and rabbit showed a different reaction to each other.

Our experimental results :

Exp. 1 showed a myosis of $2.7 \mathrm{~mm}$ after 23 hours and showed a stronger myosis than on the healthy side.

Exp. 2.

3 hours after the instillation it contracted from $11.0 \mathrm{~mm}$ to $3.5 \mathrm{~mm}$ and after 23 hours it recovered almost completely and the pupil of the healthy side took almost the same progress as above, and showed a myosis of about $2.0 \mathrm{~mm}$.

Exp. 3.

2 hours after the instillation of 1 drop of $1 \%$ ergotamine the pupil on the operated side contracted from $12.5 \mathrm{~mm}$ to $6.0 \mathrm{~mm}$ and 23 hours after the instillation it contracted as small as $2.0 \mathrm{~mm}$ and the pupil on the healthy side showed a myosis of almost the same degree. The pupil on the operated side recovered as far as $8.5 \mathrm{~mm}$ after 47 hours and $12.0 \mathrm{~mm}$ after 69 hours.

\section{Stimulation of Sciatic Nerve.}

Experimental Method.

After the subcutaneous injection of $0.005 \mathrm{~g}$ morphium hydrochloricum per kilo boby weight the dog was fixed with the face on to an animal holder, one side of the sciatic nerve was exposed and severed. A 1.7 volt Yai's dry cell and a Porter inductorium, and platimnum electrode were used. In the present experiment the coil distance was 
kept $12 \mathrm{~cm}$ and the inclination of the secondary coil was $45^{\circ}$ throughout. The central cut-end of the sciatic nerve was stimulated. (Table II).

\section{TABLE II.}

The stimulation experiment of the sciatic nerve.

\begin{tabular}{|c|c|c|c|c|c|c|}
\hline \multirow{2}{*}{ Dog No. } & \multirow{2}{*}{$\begin{array}{c}\text { Days after } \\
\text { extirpation } \\
\text { of l. cervical } \\
\text { symp. } \\
\text { ganglion }\end{array}$} & \multirow{2}{*}{$\begin{array}{l}\text { Stimula- } \\
\text { tion of } \\
\text { sciatic } \\
\text { nerve }\end{array}$} & \multicolumn{2}{|c|}{$\begin{array}{l}\text { Diameter of pupil on } \\
\text { right (healthy) } \\
\text { side } \mathrm{mm}\end{array}$} & \multicolumn{2}{|c|}{$\begin{array}{l}\text { Diameter of pupil of } \\
\text { left (operated) } \\
\text { side mm }\end{array}$} \\
\hline & & & $\begin{array}{c}\text { Before } \\
\text { stimulation }\end{array}$ & $\begin{array}{c}\text { After } \\
\text { stimulation }\end{array}$ & $\begin{array}{c}\text { Before } \\
\text { stimulation }\end{array}$ & $\begin{array}{c}\text { After } \\
\text { stimulation }\end{array}$ \\
\hline 4. & $471 d$ & $r_{1}$ & \multirow{2}{*}{4.5} & \multirow{2}{*}{6.5} & 37 & \\
\hline 22 & 44 & L & & & 4.0 & 5.0 \\
\hline 9 & 343 & $\mathrm{R}$ & 4.5 & 5,5 & 3.5 & 4.0 \\
\hline 23 & 51 & L & 2.8 & 5.0 & 1.8 & 2.8 \\
\hline \multirow[t]{2}{*}{7} & 389 & $\mathbf{R}$ & 2.8 & 5.5 & 2.0 & 2.5 \\
\hline & $\begin{array}{l}\text { Destruction } \\
\text { of right g. } \\
\text { ciliare }\end{array}$ & & \multicolumn{2}{|c|}{$\begin{array}{l}\text { Diameter of pupil on left } \\
\text { (healthy) side, } \mathrm{mm}\end{array}$} & \multicolumn{2}{|c|}{$\begin{array}{l}\text { Diameter of pupil on the } \\
\text { right (operated) side, mm. } \\
\text { constrieted slightly by } \\
\text { Acetylcholine }\end{array}$} \\
\hline 18 & $88 d$ & $\mathrm{R}$ & 2.5 & 5.0 & 7.5 & 8.5 \\
\hline 19 & 101 & L & 2.0 & 3.5 & 5.5 & 7.2 \\
\hline 20 & 94 & $\mathrm{R}$ & 2.8 & 5.3 & 2.5 & 3.3 \\
\hline
\end{tabular}

After the g. cervicale superius or the g. ciliare of one side had been extirpated, the stimulation of the central out-end of the sciatic nerve caused a reflex mydriasis of the pupil on the operated side in all cases (the mydriasis of 0.5 to $1.7 \mathrm{~mm}$, on an average $0.94 \mathrm{~mm}$ ), but compared with the dilation on the healthy side, its degree was extremely smaller. $(1.0 \mathrm{~mm}-2.7 \mathrm{~mm}$ on an average).

\section{Discussron.}

According to Behr $r^{9)}$ the movement of the pupil has 3 different types.

1. The increase of the tone of the iris muscle of one side, while the tone on the gther side is unchanged.

2. The muscle tone of the iris on one side is decreased, whereas that on the other side is unchanged, showing only the passive increase of the tone.

3. Combining 1 and 2 types; i.e., the active increase of the tone of muscles of one side together with the active diminution of the tone of the muscles on the other side. 
Behris) concludes that the light reaction of the pupil belongs to the third type, and that the convergence to the first type and the sensory reaction and the mental reaction belong to the second type when the stimulus is weak, and to the third type first when the stimulus is strong from his long clinical experience, from the nature of the light reaction in the paralysis of sympathetic nerve of one side and from 2 cases of iris-injury. (In one case the dilator plate, which keeps the sphincter iridis muscle in the right position, is separated from the stroma by the crack from injury, and in the other case an almost circular hole is formed by a punctured wound in the infancy through all the layers of iris.)

Poo ${ }^{8)}$ opposed Behr's theory and, after making clear the difference between the views of $\mathrm{Behr}$ and himself, said that he could not reach any definite conclusion as $\mathrm{Behr^{9) }}$ and Kitahara ${ }^{10)}$ agree with the opinion of Poos from the experimental basis. Behr and his supporters theory is based on the idea of the "reciprocal innervation" in the skeletal muscle, which is proposed by Sherrington.

The iris consists of the $\mathrm{m}$. sphincter and $\mathrm{m}$. dilatator, the latter is arranged radial, with one end fixed and the other end free, partly attaching to the sphincter muscle, while the $\mathrm{m}$. sphincter is arranged circulary and supported by the m. dilatator pupillae. Therefore when the sphincter is relaxed, the dilator increases its tone passively (shortening) and contracts toward the fixing point, ultimately causing a pupillary dilation. The pupil-dilation after destroying the $g$. ciliare or by the instillation of atropine is carried on by the same mechanism. In the case of the tone-diminution of the m. dilatator pupillae after extirpating the g. cervicale sup. a new equilibrium is established in the sphincter by the relative increase of its tone, and the pupil contracts slightly, but the change in the size of the pupil by the destruction of the g. ciliare is far greater, compared with that by the extirpation of the $g$. cervicale sup. Thus the relaxation of the muscular tone gives rise to a passive tone-increase on the other side of the muscle. A very free movement of the sphincter is due to the anatomical relation and it also is microcopically shown that the sphincter is far stronger than the dilator. So, when the tone of the sphincter increases, the parallel action of the relaxation of the dilator is not a matter of absolute necessity. Although Behr insists that, when the g. cervicale superius of one side has been extirpated, the pupil on the healthy side shows more quick and exact light reaction compared with that on the operated side, and attributes this to affording proof of the existence of the co- 
operative relaxation of the dilatator pupillae. However, from our foregoing physiological and pharmacological experiments it is evident that the co-operative action of the dilatator pupillae is caused by the existence of the tone of the sympathetic nerve and there is no need to consider the active relaxation of the dilatator pupillae. Poos also stated that the degree of the sphincter action in the light reaction corresponded to the strength of the reflexive stimulus, when the pupil was constricted against the tone of the dilator, the constriction-stimulus. was reduced, and the tone of the dilatator pupillae was lost, and that the dilator in this case acted only passively and tried to maintain the pupillary diameter, which the sphincter determined, by "Sperrung."

Another problem is the entire loss of the light reaction after the impairment of the parasympathetic innervation of the head. Anderson, although once touched the question, did not discuss on the question of the co-operative action of the dilatator pupillae. So far as I am aware $I$ can not find any discussion on this question before.

Next, we come to the question of the pupillary dilation caused by the painful stimulus. This phenomenon is explained as the reaction of the sympathetic nerve, but, as we stated in the introduction, Bechtere $\mathrm{w}^{11)}$ and Bra unstein ${ }^{12)}$ ascribed it to the result of the diminishing impulse transmitted along the oculomotorius nerve. Karplus and Kreidl ${ }^{13-16)}$ stated that the impulse which started from the sympathetic nerve centre in the midbrain was transmitted along the sympathetic nerve in the neck and caused the constriction of the pupil and at the same time the oculomotor nerve was affected inhibitorily by another impulse and caused the pupillary dilation at the end. Behr said that in the sensory reaction he recognized the excitation of the sympathetic nerve and the inhibition of the parasympathetic nerve. In our present experiments we observed the pupillary dilation by the stimulation of the sciatic nerve both in case of the extirpation of the g. cervicale superius as well as in case of the destruction of the $g$. ciliare. Thus the double innervation of the sphincter becomes a question of discussion. This was first introduced by Jose $\mathrm{ph}^{17)}$ and supported by the experiment of Poos and Kitahara ${ }^{10)}$. The basis of this theory is that the inhibition of the sphincter and the augmentation of the dilatator pupillae are caused by the drugs, which augmented the sympathetic nerve on the extirpated preparation. If we want to explain the result of stimulating the sciatic nerve from this theory we must assume that the sphincter receives a central and a peripheral inhibition. Ha sim oto ${ }^{18)}$ discovered that the non-medullated network 
containing nervous cells were bedded in the deep layer of the sphincter besides the findings during his histological investigation into the iris nerve of the rabbit, and described that network as the ending of the oculomotor nerve and consented to the theory of double innervation of the sphincter pupillae, but his anatomical and histological investigations were not said to be quite enough.

\section{Conclusion.}

The author used 4 dogs and destroyed that g. ciliare of one side, holding the pupil on the other side under control, and by the physiological and pharmacological observations of the pupil on the operated side he obtained the following results.

1. The destruction of the g. ciliare of one side in the dog causes the dilation of the pupil to $11.2 \mathrm{~mm}$ on an average and the reaction to -light entirely disappeares.

2. 2 to 4 days after the destruction of the g. ciliare there appears the action of pilocarpine on the pupil of the operated side, 4-26 days after it that of acetylcholine, and 17-51 days after the operation that of eserine.

3. When the g. ciliare of one side is destroyed, the constricted pupil on the operated side by the instillation of pilocarpine dilates to the maximum by cocaine and atropine.

4. The stimulation of the central cut-end of the sciatic never after either the g. cervicale sup. or the g. ciliare of one side is deprived of, the pupil on the operated side dilates in both cases in a far minor degree than that on the controlled healthy side.

5. The dilated pupil which is caused by the destruction of the g. ciliare of one side constricted strongly by ergotamine.

From the above discoveries and those in the preceeding experiments on the extirpation of the cervical sympathetic ganglion of one side we conclude as follows.

1. The diminution of the tone of the sphincter pupillae soon induces the relative increase in the tone of the dilatator pupillae.

2. The existence of the tone of the cervical sympathetic nerve on the dilatator pupillae increases pronouncedly the amplitude of the movement of the sphincter pupillae.

3. In case of an increase of the tone of the sphincter pupillae, the co-operative diminution of the tone of an antagonistic dilatator pupillae is not necessary, but in case of an increase of the tone of the 
dilatator pupillae, on the contrary, necessarily accompanies an inhibition of the tone of the sphincter pupillae.

The author sincerely thanks to Prof. M. I tagaki and Prof. Y. Shoji for their kind advice and criticism rendered during the process of this research.

\section{REFERENCES.}

(1) Ellenberger, W. and Baum, H.: Anatomie des Hundes. Berlin 1891, 512.

(2) Jegorow, J.; Arch. Slav. de Biol. 1887, 3, 322, Cited from Byrne J.G. Studies on the physiology of the eye, London 1933,40 .

(3) Schultz, P.: Arch. f. Physiol. 1898, 70.

(4) Anderson: J. Physiol. 1905, 33, 414.

(5) Araya, S.: Nippon Gankagakkai Zassi 1929, 33, 1, 97 and 250.

(6) Shen, S.C. and Canno n, W.B.: Chinese J. Physiol, 1936, 10, 359.

(7) Hess. W.R.: Klin. Monatsbl. f. Augenheilk. 1925, 75, 295.

(8) Poos, Fr.: Arch. f. exp. Pathol. u. Pharm. 1927, 126, 307.

(9) Behr, C.: Greefe's Arch. 1933, 130, 411.

(10) Kitahara, E.: Nippon Gankagakkai Zassi 1981, 3, 5.

(11) Bechterew: Pfüger's Arch. 1883, 31, 60.

(12) Braunstein, E.P.: Die Lehre von der Innervation der Pupillenerweiterung, Wiesbaden 1894, 93 .

(13) Karplus, J.P. and Kreidl, A.: Pfüger's Arch. 1909, 129, 138.

(14) Id.: Ibid., 1910, 135, 401.

(15) Id.: Ibid, 1912, 143, 109.

(16) Id.: Ibid., 1918, 171, 192. 